\title{
Effect of temperature and dissolved oxygen on swimming performance in crucian carp
}

\author{
Liu-Yi Penghan, Zhen-Dong Cao, Shi-Jian Fu* \\ Laboratory of Evolutionary Physiology and Behavior, Chongqing Key Laboratory of Animal Biology, \\ Chongqing Normal University, Chongqing 400047, PR China
}

\begin{abstract}
Changing environmental conditions may affect the swimming performance of fish by affecting energy sources through changes in temperature and concentration of dissolved oxygen (DO). It has become increasingly important to investigate the effect of temperature and DO on the swimming performance of fish species as hypoxia in aquatic environments worldwide is increasing due to the effects of anthropogenic global warming. To test how different swimming modes respond to thermal and DO changes, 3 measures of swimming performance were tested: critical swimming speed $\left(U_{\text {crit }}\right)$, constant acceleration speed $\left(U_{\text {cat }}\right)$, and maximum speed during a fast-start $\left(U_{\text {fast }}\right)$. The changes in these 3 aspects of swimming performance in juvenile crucian carp Carassius carassius were quantified at 2 different temperatures $\left(10\right.$ and $\left.20^{\circ} \mathrm{C}\right)$ and 3 different $\mathrm{DO}$ concentrations $\left(2.5,5\right.$, and $\left.9 \mathrm{mg} \mathrm{l}^{-1}\right)$. $U_{\text {cat }}$ was ca. 110 to $156 \%$ of $U_{\text {crit, }}$ whereas $U_{\text {fast }}$ was ca. 394 to $472 \%$ of $U_{\text {crit }}$ depending on the experimental conditions. Temperature had a significant effect on all 3 measures of swimming performance, whereas DO had significant effects only on $U_{\text {cat }}$ and $U_{\text {crit }}$ ( $U_{\text {crit }}$ but not $U_{\text {cat }}$ decreased in the $2.5 \mathrm{mg} \mathrm{l}^{-1} \mathrm{DO}$ group). The active metabolic rate $\left(\mathrm{MO}_{2 \text { active }}\right)$ under the different experimental conditions suggested that the decrease in $U_{\text {crit }}$ at a lower temperature and DO level could be partially explained by a decrease in oxygen uptake capacity. These results indicate that all 3 swimming measurements should be used when addressing how temperature affects swimming performance.
\end{abstract}

KEY WORDS: Aerobic and anaerobic locomotion - Constant acceleration speed - Critical swimming speed · Crucian carp · Environmental condition · Fast-start swimming performance · Swimming performance

\section{INTRODUCTION}

Swimming is an important physiological activity and a survival-determining function for fish because it plays a role in food capture, predator avoidance and reproductive behavior. Swimming performance in fish can be classified as either steady or unsteady (Webb 1984). Steady swimming describes constantspeed locomotion in a straight line and is commonly employed in nature during competition for limited resources, such as searching for food, obtaining mates or seeking favorable abiotic conditions (Plaut 2001, Domenici 2003, Blake 2004). Since Brett (1964),

${ }^{*}$ Corresponding author: shijianfu9@hotmail.com the most common method of measuring the steady swimming capability of fish has involved determining the critical swimming speed $\left(U_{\text {crit, }}\right.$ i.e. speed at which a fish can no longer maintain position or the maximum sustainable swimming speed) (Beamish 1966, Hammer 1995, Kolok 1999). Although fish rely on anaerobic metabolism to different degrees while reaching $U_{\text {crit }}$ (Nelson et al. 1996), $U_{\text {crit }}$ is highly correlated with active metabolic rate $\left(\mathrm{MO}_{2 a c t i v e}\right.$, i.e. the maximum oxygen uptake capacity during the $U_{\text {crit }}$ test) and is widely accepted as an indicator for aerobic swimming performance. Thus, $U_{\text {crit }}$ is most likely limited by oxygen delivery, metabolite supply and/or

(C) The authors 2014. Open Access under Creative Commons by Attribution Licence. Use, distribution and reproduction are unrestricted. Authors and original publication must be credited. 
the buildup of waste products (Reidy et al. 2000, Richards et al. 2002). The constant acceleration speed ( $U_{\text {cati }}$ duration of minutes) and fast-start swimming ( $U_{\text {fasti }}$ duration of seconds) have been viewed as forms of unsteady swimming, which are highly important in evading predatory strikes (Webb 1986, Katzir \& Camhi 1993, Walker et al. 2005). The $U_{\text {fast }}$ test, which is completed in seconds, is powered by intracellular stores of adenosine triphosphate (ATP) and creatine phosphate $(\mathrm{PCr})$ and is most likely limited by neuromuscular morphology and physiology (Reidy et al. 2000). The $U_{\text {cat }}$ test in fish generally involves the use of 3 endogenous fuels stored within the white muscle: glycogen, ATP and PCr. In the early stages of acceleration swimming, energy is largely derived from the breakdown of $\mathrm{PCr}$ and ATP (Dobson \& Hochachka 1987, Marras et al. 2010), whereas glycogenolysis provides the majority of the ATP required to sustain muscular exertion at later stages (Dobson \& Hochachka 1987, Wood 1991). Thus, $U_{\text {cat }}$ may be more closely related to anaerobic metabolic capacity in fish. Nevertheless, the energy sources used and the limiting factors of performance vary profoundly among the 3 measures of swimming performance.

Because of the temporal and spatial patchiness of fish environments, variations in temperature and dissolved oxygen (DO) are environmentally relevant physiological challenges that can dictate a species' ecological distribution and Darwinian fitness. Thus, how the swimming performance of fish is affected by variations in temperature and DO may be critical for their survival in the field (Perry et al. 2005, Mandic et al. 2009). Changes in temperature and levels of DO have diverse effects on oxygen availability and metabolite flux, as well as intracellular stores of ATP and $\mathrm{PCr}_{\text {, }}$ and endogenous fuels stored within the white muscle, which are limiting factors of $U_{\text {crit }}, U_{\text {fast }}$ and $U_{\text {cat, }}$ respectively. Thus, environmental changes may affect different swimming performances in various physiological manners. The response of different swimming modes may be critical for survival in the field. In recent years, hypoxia in aquatic environments worldwide has increased due to the effects of anthropogenic global warming (Diaz \& Rosenberg 2008, Pörtner \& Farrell 2008, Roze et al. 2013). Therefore, it has become increasingly important to investigate the effect of temperature and DO on the swimming performance of fish species. Theoretically, a temperature decrease may have a universal negative effect on all 3 measures of swimming performance due to changes in the biochemical reaction rate. A decrease in DO may result in a more depressed aer- obic swimming performance (i.e. $U_{\text {crit }}$ than the other 2 swimming performances. A depressed $U_{\text {crit }}$ under lower temperatures and DO concentrations has been widely documented (Pang et al. 2011, Zhao et al. 2012); however, little work has been performed on $U_{\text {fast }}$ and $U_{\text {cat }}$ (Lefrançois et al. 2005, Lefrançois \& Domenici 2006, Wang et al. 2012). Furthermore, no study has investigated the effects of different environmental changes on the different swimming capacities within a single fish species. Thus, the main objective of this study was to investigate the responses of 3 different swimming performance parameters to a suite of environmental stressors.

To achieve our goal, we selected crucian carp Carassius carassius as the experimental animal because it is widely distributed in varied aquatic environments and is highly adaptive to variations in diverse environments. Temperature and DO were selected as the environmental factors to be modified because they are the most frequently encountered and environmentally relevant physiological challenges (Randall \& Brauner 1991, Claireaux et al. 2000). The low temperature $\left(10^{\circ} \mathrm{C}\right)$ selected in this study simulated the environment of the crucian carp in winter, whereas the hypoxic level simulated the extreme hypoxia situation in summer according to data on local water bodies in Chongqing, China. We also measured $\mathrm{MO}_{2 \text { active }}$ as indicated by the oxygen consumption rate $\left(\mathrm{MO}_{2}\right)$ during the $U_{\text {crit }}$ test to investigate the role of oxygen uptake capacity and swimming efficiency on the possible change of $U_{\text {crit }}$ among different experimental conditions.

\section{MATERIALS AND METHODS}

\section{Animals and maintenance}

Juvenile crucian carp Carassius carassius $(\mathrm{n}=200$ ) were purchased from the Fisheries Hatchery of Hechuan Aquaculture School (Hechuan, Chongqing City, China) and were acclimated for 1 mo in a recirculating water tank system (350 l) before the experiment. All experiments were conducted according to the Guidelines on the Humane Treatment of Laboratory Animals established by the Ministry of Science and Technology of the People's Republic of China. During the acclimation, the temperature of the dechlorinated tap water was maintained at $20^{\circ} \mathrm{C}$ $\left( \pm 0.5^{\circ} \mathrm{C}\right)$, and DO was maintained at near saturation (approximately $9 \mathrm{mg} \mathrm{l}^{-1}$ ). Fish were fed to satiation once daily on a commercial diet (Tongwei aquatic feed; dietary composition: $41.2 \pm 0.9 \%$ protein; $8.5 \pm$ 
$0.5 \%$ lipid; $25.7 \pm 1.2 \%$ carbohydrate and $12.3 \pm$ $0.4 \%$ ash). The photoperiod was established as 12:12 h light:dark to simulate the natural light cycle. Fish were fasted for $24 \mathrm{~h}$ before any measurement. After the acclimation period, healthy fish of similar size were selected as the experimental fish.

\section{Experimental design}

The fish were divided into 4 groups with 24 individuals within each group (5.96 to $11.95 \mathrm{~g}, 5.96$ to $7.71 \mathrm{~cm}$; see details in Table 1). Fish in the control group were transferred to a rearing tank with identical conditions to those of the acclimation period, i.e. $20^{\circ} \mathrm{C}$ and $9 \mathrm{mg} \mathrm{O}_{2} \mathrm{I}^{-1}$. To investigate the effect of temperature on the swimming performance of crucian carp, 24 fish were transferred to an identical rearing tank under similar conditions to the control treatment, however, the temperature was decreased by $1^{\circ} \mathrm{C} \mathrm{d}{ }^{-1}$ until $10^{\circ} \mathrm{C}$ was reached (Pang et al. 2011, $2013,2014)$. The fish were maintained at the experimental temperature by the thermo-regulated water reservoir for another $4 \mathrm{wk}$ before experimental measurements were taken. To investigate the effect of DO on swimming performance, the other 2 groups of fish were maintained at $20^{\circ} \mathrm{C}$, however DO levels were kept at 2 hypoxic levels: $5.0 \mathrm{mg} \mathrm{O}_{2} \mathrm{l}^{-1}(11.20 \mathrm{kPa})$ and $2.5 \mathrm{mg} \mathrm{O}_{2} \mathrm{l}^{-1}(5.60 \mathrm{kPa})$ which were maintained by water supplied from a 3501 reservoir tank covered with translucent plastic and the with water bubbled with nitrogen to achieve the target DO levels. DO was monitored by DO probes (HQ30, Hach Company). Each group was exercised using 3 different measures of swimming performance, i.e. $U_{\text {fast, }} U_{\text {cat }}$ and $U_{\text {crit }} \cdot \mathrm{MO}_{2}$ was also measured during the $U_{\text {crit }}$ test (see 'Measurement of $U_{\text {crit }}$ and swimming $\mathrm{MO}_{2}$ ' below for more details).

\section{Experimental facility and measurements}

Measurement of $U_{\text {fast }}$

$U_{\text {fast }}$ was measured with a device developed by the Laboratory of Evolutionary Physiology and Behavior, Chongqing Normal University (see Yan et al. 2012 for details). The device included a high-speed camera (A504K, Basler; 500 frames $\mathrm{s}^{-1}$ ) and an LED matrix light source and sink (engraved with $1 \mathrm{~cm}^{-1}$ grid lines on the bottom). The fish were anesthetized with neutralized tricaine methane sulfonate (MS-222, $50 \mathrm{mg}$ $\mathrm{l}^{-1}$ ) and dorsally marked at the center of the mass position with titanium oxide. The duration of the entire process was less than $30 \mathrm{~s}$, and fish were allowed to recover for $4 \mathrm{~h}$ following the procedure. Fish from each group were then gently herded toward the acclimation zone of the $U_{\text {fast }}$ experimental system and allowed to rest for another $1 \mathrm{~h}$ in all experimental groups (Yan et al. 2013). The depth of the water in the tank was $10 \mathrm{~cm}$. DO was maintained at saturation, except in the 2 hypoxic groups (the DO levels were allowed a variation of $\pm 0.1 \mathrm{mg} \mathrm{l}^{-1}$ ). Water temperature in the swimming chamber was maintained at either 10 (for the low temperature group only) or $20 \pm 0.1^{\circ} \mathrm{C}$. An individual fish was then introduced into the filming zone through an alleyway. Escape responses were elicited by an electrical impulse

Table 1. Experimental conditions and body sizes of crucian carp in different treatment groups. $U_{\text {crit: }}$ critical swimming speed; $U_{\text {cat }}$ : constant acceleration speed; $U_{\text {fast }}$ : macximum speed during a fast-start

\begin{tabular}{|c|c|c|c|c|c|c|c|}
\hline \multirow{2}{*}{ Treatment } & \multicolumn{2}{|c|}{ Rearing condition } & \multicolumn{2}{|c|}{ Testing condition } & \multirow{2}{*}{$\begin{array}{l}\text { Measured } \\
\text { variables }\end{array}$} & \multirow{2}{*}{$\begin{array}{c}\text { Body mass } \\
(\text { mean } \pm \mathrm{SE} \\
\mathrm{g})\end{array}$} & \multirow{2}{*}{$\begin{array}{c}\text { Body length } \\
(\text { mean } \pm \text { SE, } \\
\mathrm{cm})\end{array}$} \\
\hline & $\begin{array}{c}\text { Temperature } \\
\left({ }^{\circ} \mathrm{C}\right)\end{array}$ & $\begin{array}{c}\mathrm{DO} \\
\left(\mathrm{mg} \mathrm{l}^{-1}\right)\end{array}$ & $\begin{array}{c}\text { Temperature } \\
\left({ }^{\circ} \mathrm{C}\right)\end{array}$ & $\begin{array}{c}\mathrm{DO} \\
\left(\mathrm{mg} \mathrm{l}^{-1}\right)\end{array}$ & & & \\
\hline Control & 20 & 9 (saturated) & 20 & 9 (saturated) & $\begin{array}{l}U_{\text {crit }} \\
U_{\text {cat }} \\
U_{\text {fast }}\end{array}$ & $\begin{array}{l}8.58 \pm 0.52 \\
9.08 \pm 0.28 \\
8.63 \pm 0.19\end{array}$ & $\begin{array}{l}6.85 \pm 0.13 \\
6.80 \pm 0.06 \\
6.68 \pm 0.04\end{array}$ \\
\hline $\begin{array}{l}\text { Low temperature } \\
\text { group }\end{array}$ & 10 & 11 (saturated) & 10 & 11 (saturated) & $\begin{array}{l}U_{\text {crit }} \\
U_{\text {cat }} \\
U_{\text {fast }}\end{array}$ & $\begin{array}{l}8.97 \pm 0.28 \\
9.17 \pm 0.23 \\
9.30 \pm 0.39\end{array}$ & $\begin{array}{l}6.85 \pm 0.06 \\
6.85 \pm 0.10 \\
6.81 \pm 0.11\end{array}$ \\
\hline $\begin{array}{l}\text { Moderate DO } \\
\text { group }\end{array}$ & 20 & 9 (saturated) & 20 & 5 & $\begin{array}{l}U_{\text {crit }} \\
U_{\text {cat }} \\
U_{\text {fast }}\end{array}$ & $\begin{array}{l}9.10 \pm 0.44 \\
9.26 \pm 0.21 \\
7.99 \pm 0.25\end{array}$ & $\begin{array}{l}6.76 \pm 0.11 \\
6.86 \pm 0.05 \\
6.78 \pm 0.10\end{array}$ \\
\hline Low DO group & 20 & 9 (saturated) & 20 & 2.5 & $\begin{array}{l}U_{\text {crit }} \\
U_{\text {cat }} \\
U_{\text {fast }}\end{array}$ & $\begin{array}{l}8.89 \pm 0.44 \\
8.96 \pm 0.34 \\
8.77 \pm 0.29\end{array}$ & $\begin{array}{l}6.99 \pm 0.06 \\
7.21 \pm 0.44 \\
6.90 \pm 0.06\end{array}$ \\
\hline
\end{tabular}


(0.75 $\mathrm{V} \mathrm{cm}^{-1}$; $50 \mathrm{~ms}$ ) administered when the fish maintained a position at the center of the filming zone. The high-speed camera was used to record the entire escape process (time span: $3 \mathrm{~s}$ ). The resulting images were analyzed using image processing software (ACDsee 10, ACD Systems International) and digitized by TpsUnil and TpsDig software (http:// life.bio.sunysb.edu/morph) to define the track of the centroid of the locomotion performed by the fish during its escape response. The maximum linear velocity (i.e. $U_{\text {fast }}$ ) was calculated based on the centroid locomotion track.

\section{Measurement of $U_{\text {cat }}$}

A Brett-type swim tunnel respirometer (3.5 l; Fig. 1) was used to measure fish $U_{\text {cat }}$. Individual fish were transferred into the swim tunnel and allowed to recover for $4 \mathrm{~h}$ at a water velocity of $6 \mathrm{~cm} \mathrm{~s}^{-1}$ in all experimental groups (approximately 1 body length [BL] s ${ }^{-1}$ ) (Fu et al. 2013, Yan et al. 2013). The flow of aerated water through the respirometer was maintained continuously during this recovery period. DO and temperature were maintained as previously described in the $U_{\text {fast }}$ test. The water velocity in the swim tunnel was then steadily increased at a rate of $0.1667 \mathrm{~cm} \mathrm{~s}^{-2}$ (i.e. $10 \mathrm{~cm} \mathrm{~s}^{-1} \mathrm{~min}^{-1}$; Marras et al. 2010). The water was accelerated at this rate until the fish were exhausted. Exhaustion was defined as the fail- ure of the fish to move away from the rear honeycomb screen of the swimming chamber for at least $20 \mathrm{~s}$; the water velocity at which the fish were exhausted was used as the $U_{\text {cat }}$ value (Reidy et al. 2000, Marras et al. 2010). The $U_{\text {cat }}$ measurement process usually lasted for several minutes and showed a negligible effect on DO.

Measurement of $U_{\text {crit }}$ and swimming $\mathrm{MO}_{2}$

$U_{\text {crit }}$ and $\mathrm{MO}_{2}$ were measured using a Brett-type swim tunnel respirometer (Fig. 1). A fish was introduced into the water tunnel and left in the water at a low water velocity $\left(6 \mathrm{~cm} \mathrm{~s}^{-1}\right)$ for $4 \mathrm{~h}$ before the experiments began (Yan et al. 2012, 2013). DO and temperature were maintained as previously described. After the recovery period, the water velocity was increased by $6 \mathrm{~cm} \mathrm{~s}^{-1}$ every $20 \mathrm{~min}$ until the fish became exhausted, i.e. until the fish failed to move away from the rear honeycomb screen of the swimming chamber for a time span of $20 \mathrm{~s}$ (Lee et al. 2003 a,b, Yan et al. 2013). The swim tunnel was opened for 2 min for water exchange during the speed shift period (i.e. once every $20 \mathrm{~min}$ ). DO values in the water were recorded at 2 min intervals. DO concentration ranged from 5.1 to $4.8 \mathrm{mg} \mathrm{l}^{-1}$ and 2.6 to $2.3 \mathrm{mg} \mathrm{l}^{-1}$ for 2 hypoxic swimming conditions, whereas it never dropped below 95\% saturation for the normoxic swimming condition. The fish were removed after

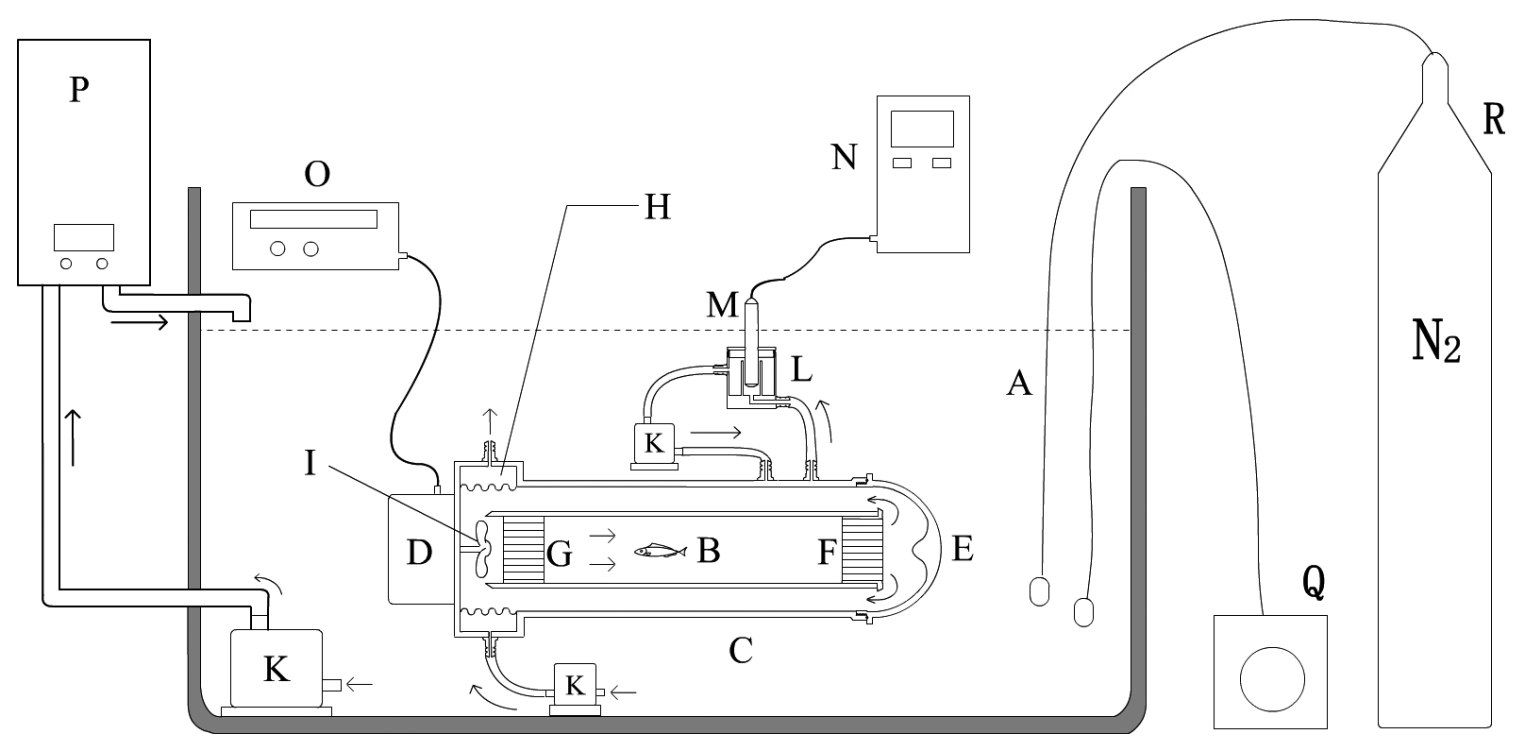

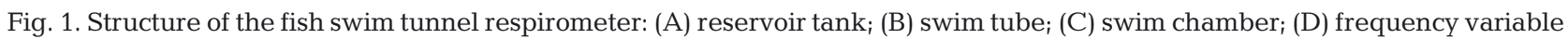
motor; (E) sealing cover; (F and G) honeycomb duct; $(\mathrm{H})$ heat exchanger; (I) propeller; (K) pump; (L) sampling bottle; (M) oxygen probe; $(\mathrm{N})$ oxygen meter; $(\mathrm{O})$ variable frequency power supply; $(\mathrm{P})$ water-processing and temperature-controlling system; $(\mathrm{Q})$ air pump $(\mathrm{R}) \mathrm{N}_{2}$ bottle 
exhaustion, and background $\mathrm{MO}_{2}$ was measured. $U_{\text {crit }}$ was calculated for each fish using Brett's equation (Brett 1964):

$$
U_{\text {crit }}=V+(t / T) \Delta V
$$

where $V$ is the highest speed at which the fish swam during the full length of the experiment $\left(\mathrm{cm} \mathrm{s}^{-1}\right), t$ is the time that the fish swam at the final speed (min), $T$ is the prescribed period of swimming per speed (20 min), and $\Delta V$ is the velocity increment $\left(6 \mathrm{~cm} \mathrm{~s}^{-1}\right)$. The $\mathrm{MO}_{2}\left(\mathrm{mg} \mathrm{kg}^{-1} \mathrm{~h}^{-1}\right)$ of each fish during swimming was calculated from the depletion of oxygen according to the following equation:

$$
\mathrm{MO}_{2}=\left(S_{t} \times 60-\mathrm{S}_{0}\right) \times V /(m / 1000)
$$

where $S_{t}$ and $S_{0}\left(\mathrm{mg} \mathrm{l}^{-1} \mathrm{~min}^{-1}\right)$ represent the decrease in the water's DO per minute with and without fish, respectively. These values were obtained from the linear regressions between time (min) and DO (mg $\mathrm{l}^{-1}$ ), where $V$ is the volume of the respirometer and $m$ is the body mass $(\mathrm{g})$ of the fish. The maximum $\mathrm{MO}_{2}$ during the $U_{\text {crit }}$ test was defined as the active $\mathrm{MO}_{2}$ $\left(\mathrm{MO}_{2 \text { active }}\right)$.

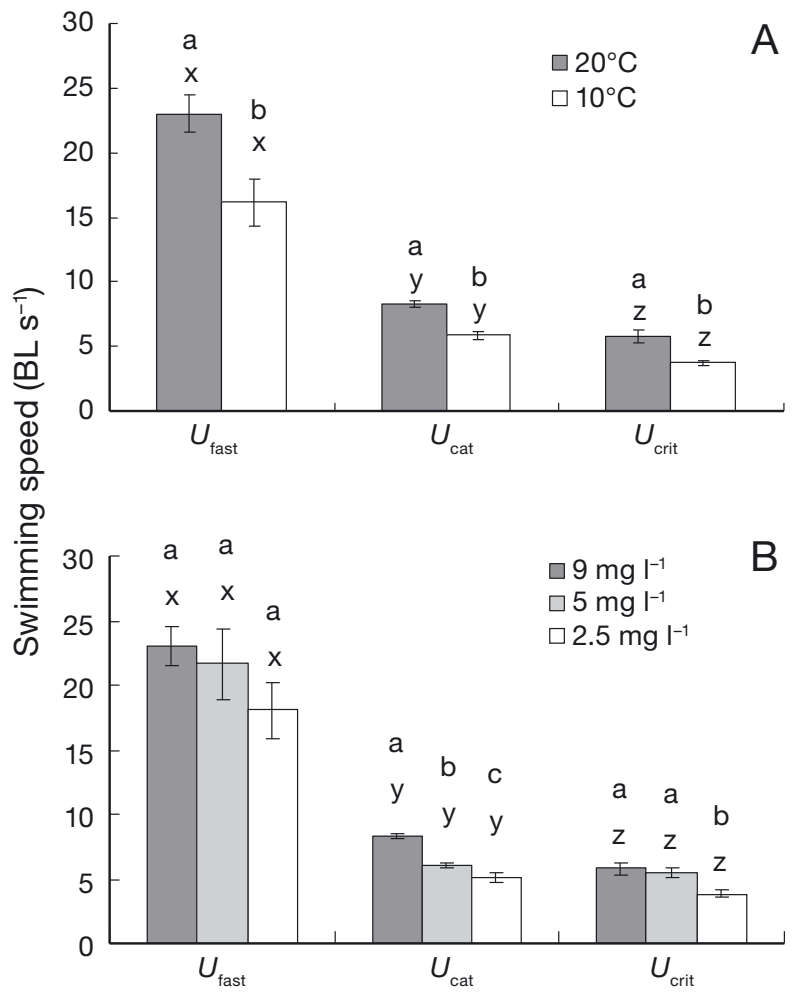

Fig. 2. Effect of (A) temperature and (B) dissolved oxygen on $U_{\text {fast }} U_{\text {cat }}$ and $U_{\text {crit }}$ levels in juvenile crucian carp. Data are mean \pm SE. Letters $(a, b$ and $c)$ above bars indicate a significant difference among the different treatment groups within $U_{\text {fast }} U_{\text {cat }}$ or $U_{\text {criti }}$ letters ( $\mathrm{x}, \mathrm{y}$ and $\mathrm{z}$ ) indicate a significant difference among $U_{\text {fast }}, U_{\text {cat }}$ and $U_{\text {crit }}$ within each treatment group

\section{Data analysis}

All 3 absolute swimming speeds $\left(\mathrm{cm} \mathrm{s}^{-1}\right)$ were converted to relative swimming speeds $\left(\mathrm{BL} \mathrm{s}^{-1}\right)$ by dividing by the body length of individual fish. All values are presented as the means $\pm \mathrm{SE}_{i} \mathrm{p}<0.05$ was used as the level of statistical significance. The effect of the experimental treatment (temperature and DO) and the measuring method $\left(U_{\text {fast, }} U_{\text {cat }}\right.$ and $\left.U_{\text {crit }}\right)$ on swimming performance was determined using a 2way ANCOVA, using body length as a covariate. Following the ANCOVA, the difference between the values of different variables within each treatment group and the difference between the values of each variable within either DO group were determined by a Duncan multiple-comparison test, whereas the difference in each variable between the 2 temperature groups was determined by a $t$-test. The effects of swimming speed and experimental treatment on swimming $\mathrm{MO}_{2}$ were determined using a 1-way ANCOVA (i.e. we performed a regression for each treatment group and compared their coefficients).

\section{RESULTS}

\section{Effect of temperature and DO on swimming performance}

There was a significant difference between $U_{\text {fast }}$ $U_{\text {cat }}$ and $U_{\text {crit }}$ within each temperature group ( $\mathrm{p}<$ 0.001) (Fig. 2A, Table 2). When measured at $20^{\circ} \mathrm{C}$, $U_{\text {crit }}$ was $5.77 \mathrm{BL} \mathrm{s}^{-1}$, whereas $U_{\text {fast }}$ and $U_{\text {cat }}$ were 399 and $144 \%$ that of $U_{\text {crit, }}$ respectively. $U_{\text {crit }}$ decreased more significantly $(35 \%)$ compared to $U_{\text {fast }}$ (35 vs. $29 \%)$ and $U_{\text {cat }}(29 \%)(\mathrm{p}<0.001)$ as the temperature decreased from 20 to $10^{\circ} \mathrm{C}$. Thus, the difference between $U_{\text {crit }}$ and the other 2 measures of swimming performance increased at a lower temperature (interaction effect, $\mathrm{p}=0.033$ ).

Table 2. The effect of body length (covariate), treatment (temperature and DO), and method ( $U_{\text {fast }}, U_{\text {cat }}$ and $\left.U_{\text {crit }}\right)$ on swimming speed of crucian carp, based on a 2-way ANCOVA. ${ }^{*} \mathrm{p}<0.05$

\begin{tabular}{|lcccccc|}
\hline & \multicolumn{3}{c}{ Temperature } & \multicolumn{3}{c|}{ DO } \\
& df & $F$ & $\mathrm{p}$ & df & $F$ & $\mathrm{p}$ \\
\hline Covariate & 1 & 0.155 & 0.696 & 1 & 1.510 & 0.224 \\
Treatment (T) & 1 & 21.81 & $<0.001^{*}$ & 2 & 4.058 & $0.022^{*}$ \\
Method (M) & 2 & 127.0 & $<0.001^{*}$ & 2 & 135.7 & $<0.001^{*}$ \\
$\mathrm{~T} \times \mathrm{M}$ & 2 & 3.717 & $0.033^{*}$ & 2 & 0.592 & 0.669 \\
\hline
\end{tabular}


There was a significant difference among $U_{\text {fast}}, U_{\text {cat }}$ and $U_{\text {crit }}$ within each DO group $(\mathrm{p}<0.001)$ (Fig. $2 \mathrm{~B}$, Table 2). $U_{\text {fast }}$ showed no significant variation among the different DO groups. However, compared to the normoxic group $\left(9 \mathrm{mg} \mathrm{l}^{-1}\right), U_{\text {cat }}$ showed a significant decrease $(p<0.05)$ of 27 and $39 \%$ in the 5 and $2.5 \mathrm{mg}$ $\mathrm{l}^{-1}$ groups, respectively. $U_{\text {crit }}$ showed no significant change as DO decreased from normoxic to $5 \mathrm{mg} \mathrm{l}^{-1}$; however, it showed a significant decrease $(34 \%)$ when measured at $2.5 \mathrm{mg} \mathrm{l}^{-1}$ compared to the normoxic group $(\mathrm{p}<0.05)$. Thus, hypoxic conditions had a more significant effect on $U_{\text {cat }}$ and $U_{\text {crit }}$ than $U_{\text {fast }}$ and the difference between $U_{\text {fast }}$ and the other 2 measures of swimming performance was increased when measured in hypoxia. Furthermore, the difference between $U_{\text {cat }}$ and $U_{\text {crit }}$ decreased from $44 \%$ in the control (normoxic) group to $10 \%$ in the $5 \mathrm{mg} \mathrm{l}^{-1}$ group.

\section{Effect of temperature and DO on metabolic rate at different swimming speeds}

$\mathrm{MO}_{2 \text { active }}$ significantly decreased (48\%) as temperature decreased from 20 to $10^{\circ} \mathrm{C}$ (Fig. $3 \mathrm{~A}$ ). $\mathrm{MO}_{2 a c t i v e}$ showed no significant change in moderate hypoxia

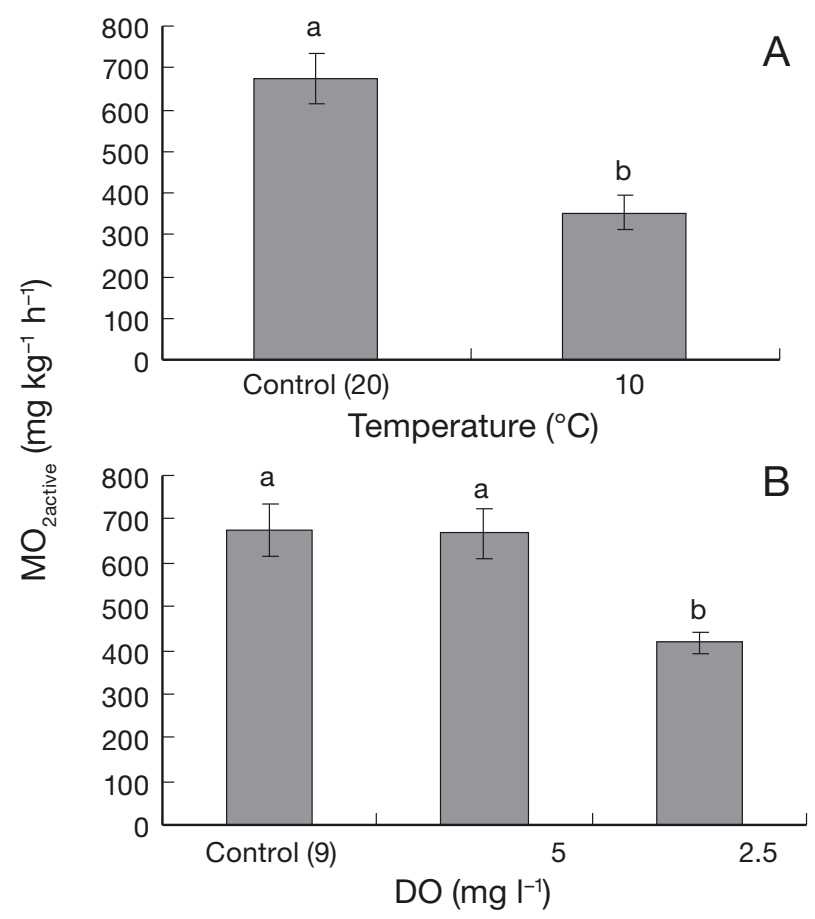

Fig. 3. Effect of (A) temperature and (B) dissolved oxygen (DO) on $\mathrm{MO}_{2 \text { active }}$ levels in juvenile crucian carp. Letters above bars indicate significant differences in $\mathrm{MO}_{2 \text { active }}$ among the different treatment groups $\left(5 \mathrm{mg} \mathrm{l}^{-1}\right)$; however, $\mathrm{MO}_{2 \text { active }}$ decreased significantly $(39 \%)$ when measured in the lowest hypoxic condition $\left(2.5 \mathrm{mg} \mathrm{l}^{-1}\right)$ (Fig. 3B).

$\mathrm{MO}_{2}$ increased significantly with swimming speed in both temperature groups $(p<0.001)$ (Fig. 4A). There was no significant difference in slopes of the $\mathrm{MO}_{2}$ speed curves between the 2 temperature groups (Fig. 4A, Table 3); however, the high temperature group showed a significantly higher $\mathrm{MO}_{2}$ compared to the low temperature group $(\mathrm{p}<0.05)$ (Fig. 4A).

$\mathrm{MO}_{2}$ increased significantly with an increase in swimming speed for all 3 experimental groups ( $p<$ 0.001) (Fig. 4B). There were no significant differences between the $\mathrm{MO}_{2}$ speed curves of the 2 hypoxic and control groups (Fig. 4B, Table 3).

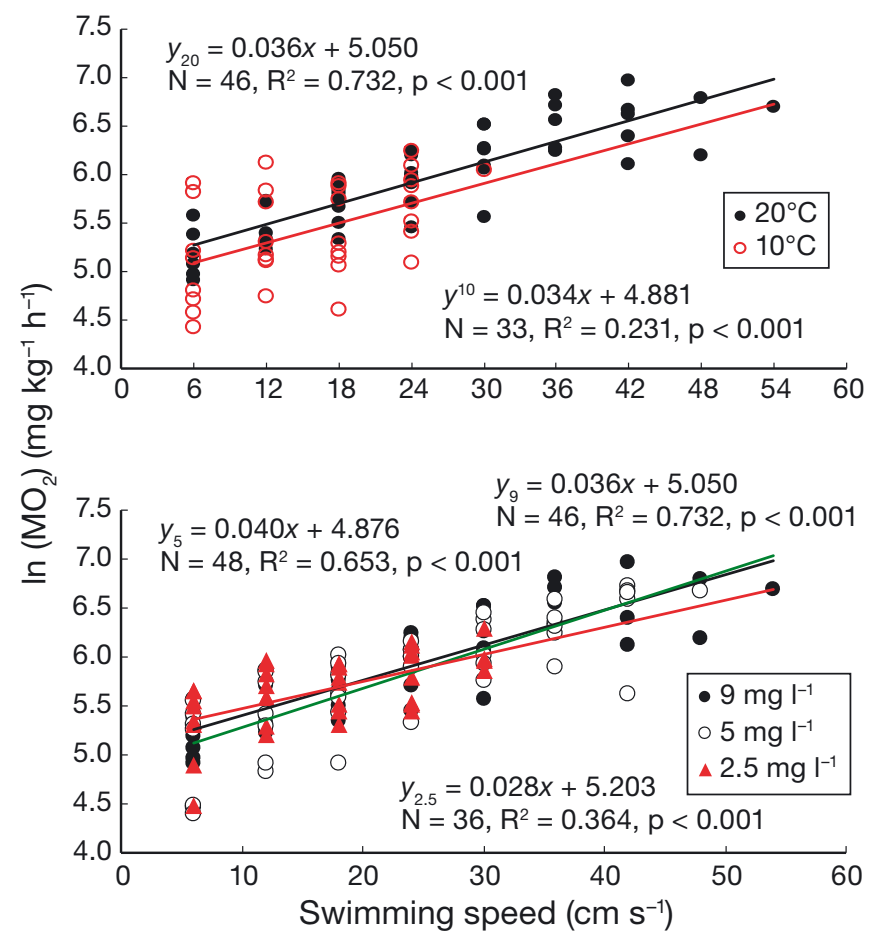

Fig. 4. $\mathrm{MO}_{2}$ swimming speed curves of juvenile crucian carp at different (A) temperatures and (B) DO concentrations

Table 3. Differences in $\mathrm{MO}_{2}$ swimming speed curves between the control and treatments using 1-way ANCOVA. See Fig. 4 for the regression equation and the intercept and slope coefficient value of each group

\begin{tabular}{|llrrrrr|}
\hline & \multirow{2}{*}{ df } & \multicolumn{2}{c}{ Intercept } & \multicolumn{2}{c|}{ Slope } \\
& & $F$ & $\mathrm{p}$ & $F$ & $\mathrm{p}$ \\
\hline Temperature & 1,78 & 45.62 & $<0.001$ & 0.039 & 0.844 \\
DO & 2,126 & 1.203 & 0.303 & 1.353 & 0.262 \\
\hline
\end{tabular}




\section{DISCUSSION}

Swimming performance is a survival-determining function, and different aspects of swimming performance are influenced by variation in an individual's environment, including temperature and DO. These environmental variables may influence swimming performance through a variety of underlying physiological processes (Arnold 1983, Garland \& Losos 1994, Feder et al. 2010). The results from this study suggest that $U_{\text {fast }}$ was the most conservative variable among the 3 swimming performance measurements and was only sensitive to thermal variation. Furthermore, $U_{\text {cat }}$ was more sensitive to change in DO than $U_{\text {crit }}$.

\section{Effect of temperature on swimming performance}

In this study, $U_{\text {fast }}, U_{\text {cat }}$ and $U_{\text {crit }}$ decreased by 28 to $38 \%$ as temperature decreased from 20 to $10^{\circ} \mathrm{C}$. These results are consistent with most published studies of fish species (Hammer 1995, Claireaux et al. 2000, Lee et al. 2003b, Fangue et al. 2008, Zeng et al. 2009, Yan et al. 2012). The reduction in swimming performance with decreasing temperature could stem from changes in both the external and internal environment of the fish. The external factor is mainly increased water viscosity, and hence, increased drag force when swimming at low temperatures, which may show similar negative effects on all 3 swimming modes (Temple \& Johnston 1997). The internal factor is mainly the reduced metabolic power and skeletal muscle contractility (both aerobic and anaerobic) (Randall \& Brauner 1991, Day \& Butler 2005), which are consequences of a reduction in the mitochondrial function of muscle tissues (Guderley 2004), decreased biochemical reaction rates (Franklin 1998), lower contents of some energy substrates ( $\mathrm{PCr}$ and ATP) in the bodies of fish living in cold water (Kieffer et al. 1994, Kieffer 2000), and/or the reduction of cardio-respiratory functions at low temperatures (Claireaux et al. 2000, Joaquim et al. 2004). The muscle contractility decided by ATP and PCr may have a crucial effect on $U_{\text {fast, }}$ whereas the muscle contractility decided by the biochemical reaction rates in either red or white muscles may show alternative effects on either $U_{\text {crit }}$ or $U_{\text {cat }}$. Furthermore, cardiorespiratory performance may mainly affect $U_{\text {crit }}$ (the transportation of oxygen and metabolites) rather than $U_{\text {cat }}$ or $U_{\text {fast }}$ which may be the reason why $U_{\text {crit }}$ was more sensitive to temperature change in crucian carp in this study. However, the effect of temperature on different swimming modes is dependent on fish species and temperature ranges. A previous study on 6 cyprinids observed that $U_{\text {crit }}$ increased by 7 to $\sim 37 \%$, whereas $U_{\text {fast }}$ increased by 26 to $\sim 103 \%$ as temperature increased from 15 to $25^{\circ} \mathrm{C}$, with $U_{\text {crit }}$ generally being much less sensitive to thermal change than $U_{\text {fast }}$ (Yan et al. 2012); results that are not consistent with the results of this study. Furthermore, Yan et al. (2012) also suggested that thermal sensitivity of $U_{\text {crit }}$ and $U_{\text {fast }}$ was negatively correlated.

\section{Effect of DO on swimming performance}

Changes in DO showed no significant effect on $U_{\text {fast, }}$ which was consistent with previous studies on European sea bass Dicentrarchus labrax and golden grey mullet Liza aurata (Lefrançois et al. 2005, Lefrançois \& Domenici 2006). The absence of a DO effect on $U_{\text {fast }}$ is easily understood because the faststart movement occurs within seconds and is mainly limited by ATP and PCr in muscle tissues, and thus may be largely independent of DO levels. However, it is notable to observe that $U_{\text {cat }}$ was more sensitive to DO change than $U_{\text {crit, }}$ as the former showed a significant decrease at a moderate DO level $\left(5 \mathrm{mg} \mathrm{l}^{-1}\right)$, whereas the latter did not. This result is surprising because $U_{\text {crit }}$ is more likely to be aerobic swimming, whereas $U_{\text {cat }}$ is more likely to be anaerobic swimming. The reason may be because the limitation of $U_{\text {crit }}$ in some fish species was caused by the mobilization, transportation and utilization of energy fuels rather than the oxygen availability. This result has been clearly demonstrated in species such as darkbarbel catfish Pelteobagrus vachelli (Fu et al. 2009), common carp Cyprinus carpio (Zhang et al. 2010) and crucian carp (Zhang et al. 2012) (a so-called additive metabolic mode compared to a locomotion priority mode in species whose swimming activity can occupy all of their cardio-respiratory capacity; Fu et al. 2011). For these types of species, a moderate DO decrease may not affect $U_{\text {crit }}$. Previous studies on mulloway Argyrosomus japonicus and darkbarbel catfish (Pang et al. 2012) observed that $U_{\text {crit }}$ showed no change with a moderate DO decrease. In the present study, $\mathrm{MO}_{2 \mathrm{active}}$ showed no decrease at a moderate DO level in crucian carp, which also supported that $U_{\text {crit }}$ was not limited by the respiratory capacity in normoxia. Furthermore, $U_{\text {cat }}$ is comprised of 2 components: an entirely aerobic component of steady swimming supported by aerobic 'red muscle' fibers instead of a component at the top end of the performance range (Peake 2008). Although $U_{\text {cat }}$ relies more on anaerobic metabolism than $U_{\text {crit, }} U_{\text {cat }}$ is dictated by 
both aerobic and anaerobic swimming, and the aerobic components of $U_{\text {cat }}$ depend more on oxygen availability than the transportation and utilization of substrates because of its shorter duration compared to $U_{\text {crit. }}$ Thus, small changes in DO will decrease $U_{\text {cat }}$. Further investigation into the effect of DO changes on $U_{\text {cat }}$ and $U_{\text {crit }}$ among fish with different metabolic modes (additive vs. priority mode) is necessary.

\section{Differences between $U_{\text {critr }} U_{\text {cat }}$ and $U_{\text {fast }}$}

At $20^{\circ} \mathrm{C}$ and normoxic DO levels, $U_{\text {crit }}$ was $5.77 \mathrm{BL}$ $\mathrm{s}^{-1}$, whereas $U_{\text {cat }}$ was $144 \%$ that of $U_{\text {crit. }}$. These results are consistent with the ranges of previously published studies. For example, $U_{\text {cat }}$ was $30 \%$ higher than $U_{\text {crit }}$ in largemouth bass Micropterus salmoides, 20 to $\sim 60 \%$ higher in rainbow trout Oncorhynchus mykiss and $77 \%$ higher in Atlantic cod Gadus morhua (Farlinger \& Beamish 1977, Farrell 2008, Reidy et al. 2000). However, because $U_{\text {cat }}$ was more sensitive to DO, the difference between $U_{\text {cat }}$ and $U_{\text {crit }}$ decreased at a moderate DO level. $U_{\text {fast }}$ was $399 \%$ that of $U_{\text {crit }}$ in the control group, which is similar to, or slightly higher than, that of other cyprinids (Yan et al. 2012).

\section{Concluding remarks}

In conclusion, the results of this study suggest that temperature change has a universal effect on all measures of swimming performance, likely due to its effects on multiple physiological and biochemical functions in fish. However, the thermal sensitivity of different swimming modes differs among fish species. The inner physiological and biochemical mechanisms and their ecological relevance require further investigation. Our results suggest that all 3 swimming measurements should be used when studying how temperature affects swimming performance. $U_{\text {cat }}$ was more sensitive to changes in DO than $U_{\text {crit, }}$ which was unanticipated. It may be because the aerobic swimming components of $U_{\text {cat }}$ depend more on oxygen availability than the transportation of energy. Among the 3 measures of swimming performance, $U_{\text {fast }}$ was the most conservative variable. The difference between $U_{\text {fast }}$ and the remaining variables was typically increased when the environmental conditions deviated from optimal conditions (i.e. when the fish were under stress). This study indicates that variations in temperature and DO variations may have a significant effect on swimming performance and the outcome of routine physiological activities in the field.
Acknowledgements. This study was funded by the National Science Foundation of China (NSFC 31172096) and the Key Project of the Natural Science Foundation of CQ (cstc2013 jjB20003).

\section{LITERATURE CITED}

Arnold SJ (1983) Morphology, performance and fitness. Am Zool 23:347-361

$>$ Beamish FWH (1966) Swimming endurance of some Northwest Atlantic fishes. J Fish Res Board Can 23:341-347

> Blake RW (2004) Fish functional design and swimming performance. J Fish Biol 65:1193-1222

> Brett JR (1964) The respiratory metabolism and swimming performance of young sockeye salmon. J Fish Res Board Can 21:1183-1226

Claireaux G, Webber DM, Lagardère JP, Kerr SR (2000) Influence of water temperature and oxygenation on the aerobic metabolic scope of Atlantic cod (Gadus morhua). J Sea Res 44:257-265

$>$ Day N, Butler PJ (2005) The effects of acclimation to reversed seasonal temperatures on the swimming performance of adult brown trout Salmo trutta. J Exp Biol 208:2683-2692

Diaz RJ, Rosenberg R (2008) Spreading dead zones and consequences for marine ecosystems. Science 321:926-929

Dobson GP, Hochachka PW (1987) Role of glycolysis in adenylate depletion and repletion during work and recovery in teleost white muscle. J Exp Biol 129:125-140

Domenici P (2003) Habitat, body design and the swimming performance of fish. In: Bels VL, Gasc JP, Casinos A (eds) Vertebrate biomechanics and evolution. BIOS Scientific Publishers, Milton Park, p 137-160

Fangue NA, Mandic M, Richards JG, Schulte PM (2008) Swimming performance and energetics as a function of temperature in killifish Fundulus heteroclitus. Physiol Biochem Zool 81:389-401

Farlinger S, Beamish FWH (1977) Effects of time and velocity increments on the critical swimming speed of largemouth bass (Micropterus salmoides). Trans Am Fish Soc 106:436-439

> Farrell AP (2008) Comparisons of swimming performance in rainbow trout using constant acceleration and critical swimming speed tests. J Fish Biol 72:693-710

Feder ME, Garland T Jr, Marden JH, Zera AJ (2010) Locomotion in response to shifting climate zones: not so fast. Annu Rev Physiol 72:167-190

Franklin CE (1998) Studies of evolutionary temperature adaptation: muscle function and locomotor performance in Antarctic fish. Clin Exp Pharmacol Physiol 25:753-756

$>$ Fu SJ, Zeng LQ, Li XM, Pang X, Cao ZD, Peng JL, Wang YX (2009) The behavioural, digestive and metabolic characteristics of fishes with different foraging strategies. J Exp Biol 212:2296-2302

Fu SJ, Brauner CJ, Cao ZD, Richards JG, Peng JL, Dhillon R, Wang YX (2011) The effect of acclimation to hypoxia and sustained exercise on subsequent hypoxia tolerance and swimming performance in goldfish (Carassius auratus). J Exp Biol 214:2080-2088

Fu C, Cao ZD, Fu SJ (2013) The effects of caudal fin loss and regeneration on the swimming performance of three cyprinid fish species with different swimming capacities. J Exp Biol 216:3164-3174

Garland T Jr, Losos JB (1994) Ecological morphology of locomotor performance in squamate reptiles. In: Wainwright PC, Reilly S (eds) Ecological morphology: integrative 
organismal biology. University of Chicago Press, Chicago, IL, p 240-302

Guderley H (2004) Locomotor performance and muscle metabolic capacities: impact of temperature and energetic status. Comp Biochem Physiol Part B Biochem Mol Biol 139:371-382

> Hammer C (1995) Fatigue and exercise tests with fish. Comp Biochem Physiol A 112:1-20

> Joaquim N, Wagner GN, Gamperl AK (2004) Cardiac function and critical swimming speed of the winter flounder (Pleuronectes americanus) at two temperatures. Comp Biochem Physiol Part A Mol Integr Physiol 138:277-285

Katzir G, Camhi JM (1993) Escape response of black mollies (Poecilia sphenops) to predatory dives of a pied kingfisher (Ceryle rudis). Copeia 1993:549-553

> Kieffer JD (2000) Limits to exhaustive exercise in fish. Comp Biochem Physiol Part A Mol Integr Physiol 126:161-179

> Kieffer J, Currie S, Tufts B (1994) Effects of environmental temperature on the metabolic and acid-base responses of rainbow trout to exhaustive exercise. J Exp Biol 194: 299-317

Kolok AS (1999) Interindividual variation in the prolonged locomotor performance of ectothermic vertebrates: a comparison of fish and herpetofaunal methodologies and a brief review of the recent fish literature. Can J Fish Aquat Sci 56:700-710

> Lee CG, Farrell AP, Lotto A, Hinch SG, Healey MC (2003a) Excess post-exercise oxygen consumption in adult sockeye (Oncorhynchus nerka) and coho (O. kisutch) salmon following critical speed swimming. J Exp Biol 206: 3253-3260

> Lee CG, Farrell AP, Lotto A, MacNutt MJ, Hinch SG, Healey $\mathrm{MC}$ (2003b) The effect of temperature on swimming performance and oxygen consumption in adult sockeye (Oncorhynchus nerka) and coho (O. kisutch) salmon stocks. J Exp Biol 206:3239-3251

> Lefrançois C, Domenici P (2006) Locomotor kinematics and behaviour in the escape response of European sea bass, Dicentrarchus labrax L., exposed to hypoxia. Mar Biol 149:969-977

- Lefrançois C, Shingles A, Domenici P (2005) The effect of hypoxia on locomotor performance and behaviour during escape in Liza aurata. J Fish Biol 67:1711-1729

Mandic M, Todgham AE, Richards JG (2009) Mechanisms and evolution of hypoxia tolerance in fish. Proc R Soc Lond B Biol Sci 276:735-744

> Marras S, Claireaux G, McKenzie DJ, Nelson JA (2010) Individual variation and repeatability in aerobic and anaerobic swimming performance of European sea bass, Dicentrarchus labrax. J Exp Biol 213:26-32

Nelson J, Tang Y, Boutilier R (1996) The effects of salinity change on the exercise performance of two Atlantic cod (Gadus morhua) populations inhabiting different environments. J Exp Biol 199:1295-1309

Pang X, Cao ZD, Fu SJ (2011) The effects of temperature on metabolic interaction between digestion and locomotion in juveniles of three cyprinid fish, Carassius auratus, Cyprinus carpio and Spinibarbus sinensis. Comp Biochem Physiol Part A Mol Integr Physiol 159:253-260

Pang X, Yuan XZ, Cao ZD, Fu SJ (2012) The effects of dissolved oxygen levels on resting oxygen consumption and swimming performance in juvenile darkbarbel catfish Peltebagrus vachelli. Acta Hydrobiol Sin 36:255-261

Pang X, Yuan XZ, Cao ZD, Fu SJ (2013) The effects of temperature and exercise training on swimming performance in juvenile qingbo (Spinibarbus sinensis). J Comp Physiol B 183:99-108
Pang X, Yuan XZ, Cao ZD, Fu SJ (2014) The effects of fasting on swimming performance in juvenile qingbo (Spinibarbus sinensis) at two temperatures. J Therm Biol 42: 25-32

Peake SJ (2008) Gait transition speed as an alternate measure of maximum aerobic capacity in fishes. J Fish Biol 72: 645-655

Perry AL, Low PJ, Ellis JR, Reynolds JD (2005) Climate change and distribution shifts in marine fishes. Science 308:1912-1915

Plaut I (2001) Critical swimming speed: its ecological relevance. Comp Biochem Physiol Part A Mol Integr Physiol 131:41-50

> Pörtner HO, Farrell AP (2008) Physiology and climate change. Science 322:690-692

Randall D, Brauner C (1991) Effects of environmental factors on exercise in fish. J Exp Biol 160:113-126

Reidy SP, Kerr SR, Nelson JA (2000) Aerobic and anaerobic swimming performance of individual Atlantic cod. J Exp Biol 203:347-357

Richards JG, Mercado AJ, Clayton CA, Heigenhauser GJ, Wood CM (2002) Substrate utilization during graded aerobic exercise in rainbow trout. J Exp Biol 205:2067-2077

Roze T, Christen F, Amerand A, Claireaux G (2013) Tradeoff between thermal sensitivity, hypoxia tolerance and growth in fish. J Therm Biol 38:98-106

Temple GK, Johnston IA (1997) The thermal dependence of fast-start performance in fish. J Therm Biol 22:391-401

> Walker JA, Ghalambor CK, Griset OL, McKenney D, Reznick DN (2005) Do faster starts increase the probability of evading predators? Funct Ecol 19:808-815

Wang F, Chen BJ, Cao ZD, Wang YX, Fu SJ (2012) The influence of starvation on fast-start performance of Spinibarbus sinensis. Acta Ecol Sin 32:291-296

Webb PW (1984) Body form, locomotion and foraging in aquatic vertebrates. Am Zool 24:107-120

Webb PW (1986) Effect of body form and response threshold on the vulnerability of four species of teleost prey attacked by largemouth bass (Micropterus salmoides). Can J Fish Aquat Sci 43:763-771

Wood CM (1991) Acid-base and ion balance, metabolism, and their interactions, after exhaustive exercise in fish. J Exp Biol 160:285-308

Yan GJ, He XK, Cao ZD, Fu SJ (2012) The trade-off between steady and unsteady swimming performance in six cyprinids at two temperatures. J Therm Biol 37:424-431

Yan GJ, He XK, Cao ZD, Fu SJ (2013) An interspecific comparison between morphology and swimming performance in cyprinids. J Evol Biol 26:1802-1815

Zeng LQ, Cao ZD, Fu SJ, Peng JL, Wang YX (2009) Effect of temperature on swimming performance in juvenile southern catfish (Silurus meridionalis). Comp Biochem Physiol A Mol Integr Physiol 153:125-130

- Zhang W, Cao ZD, Peng JL, Chen BJ, Fu SJ (2010) The effects of dissolved oxygen level on the metabolic interaction between digestion and locomotion in juvenile southern catfish (Silurus meridionalis Chen). Comp Biochem Physiol A Mol Integr Physiol 157:212-219

- Zhang W, Cao ZD, Fu SJ (2012) The effects of dissolved oxygen levels on the metabolic interaction between digestion and locomotion in Cyprinid fishes with different locomotive and digestive performances. J Comp Physiol B 182: $641-650$

Zhao WW, Pang X, Peng JL, Cao ZD, Fu SJ (2012) The effects of hypoxia acclimation, exercise training and fasting on swimming performance in juvenile qingbo (Spinibarbus sinensis). Fish Physiol Biochem 38:1367-1377 